\title{
Nontargeted Pattern Recognition in the Search for Pyrolysis Gas Chromatography/Mass Spectrometry Resin Markers in Historic Lacquered Objects
}

Supporting information

Louise Decq, ${ }^{*+*}$ Emmanuel Abatih, ${ }^{\sharp}$ Henk Van Keulen, ${ }^{\infty}$ Viviane Leyman, ${ }^{\circledR}$ Vincent Cattersel, ${ }^{\ddagger}$ Delphine

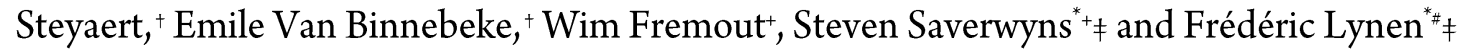

${ }^{+}$Department Laboratories, Royal Institute for Cultural Heritage (KIK-IRPA), Jubelpark 1, 1000 Brussels, Belgium.

"Separation Science Group, Department of Organic and Macromolecular Chemistry, Ghent University, Krijgslaan 281, 9000 Ghent, Belgium.

\# Fostering Innovative Research based on Evidence (FIRE), Ghent University, Krijgslaan 281, 9000 Ghent, Belgium.

${ }^{\infty}$ Cultural Heritage Agency of the Netherlands, Hobbemastraat 221071 ZC Amsterdam, The Netherlands

${ }^{\Im}$ Meise Botanic Garden, Nieuwelaan 38, 1860 Meise, Belgium

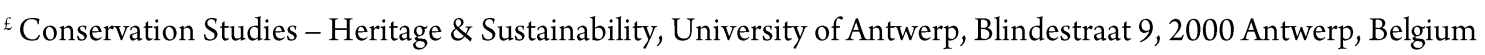

+ Royal Museums of Art and History (RMAH), Jubelpark 10, 1000 Brussels, Belgium

Additional to table 2 , structural information and mass spectra of the listed molecules. 
Structural information and representative mass spectra regarding the molecules represented in table 2 of the main article.

MARKERS FOR CON-SAM

\section{CONSAM 1}

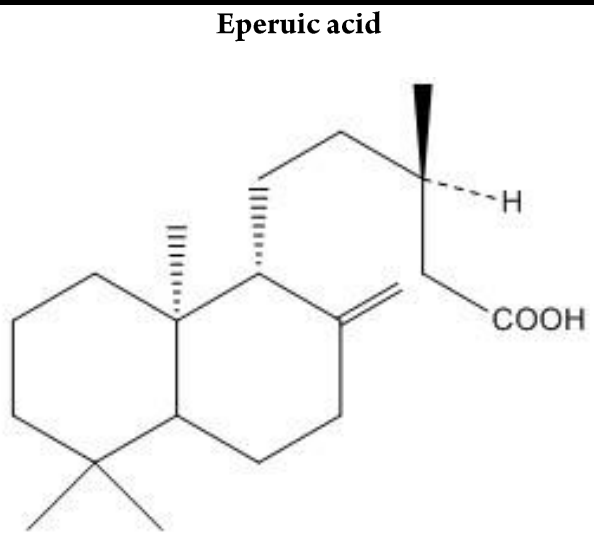

Chemical Formula: $\mathrm{C}_{20} \mathrm{H}_{34} \mathrm{O}_{2}$

Exact Mass: 306,3

Molecular Weight: 306,5

$\mathrm{m} / \mathrm{z}: 306.3(100.0 \%), 307.3(21.6 \%), 308.3(2.2 \%)$

Elemental Analysis: C, $78.38 ; \mathrm{H}, 11.18 ; \mathrm{O}, 10.44$
Eperuic acid ME

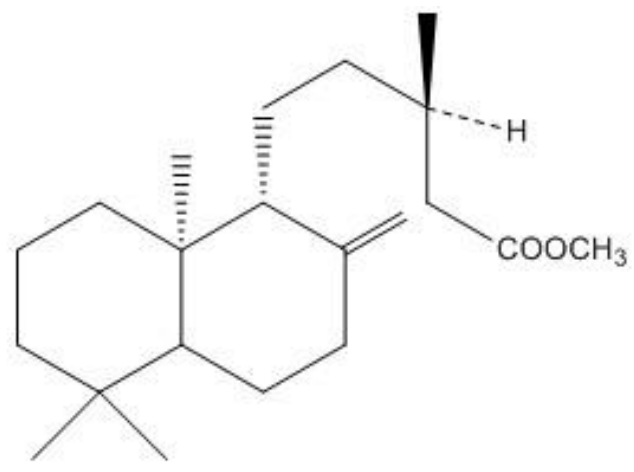

Chemical Formula: $\mathrm{C}_{21} \mathrm{H}_{36} \mathrm{O}_{2}$ Exact Mass: 320,3

Molecular Weight: 320,5

$\mathrm{m} / \mathrm{z}: 320.3(100.0 \%), 321.3(22.7 \%), 322.3(2.5 \%)$

Elemental Analysis: C, 78.70; H, 11.32; O, 9.98

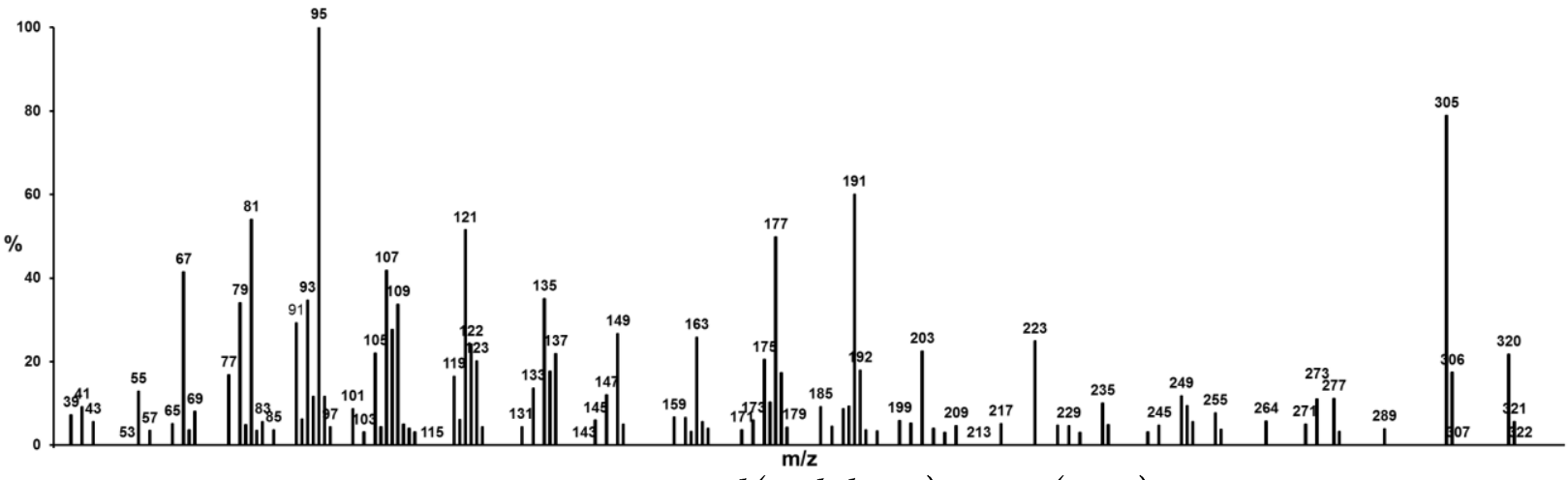

CONSAM1 - Eperuic acid (methyl ester) RI 2221 (20.25) 


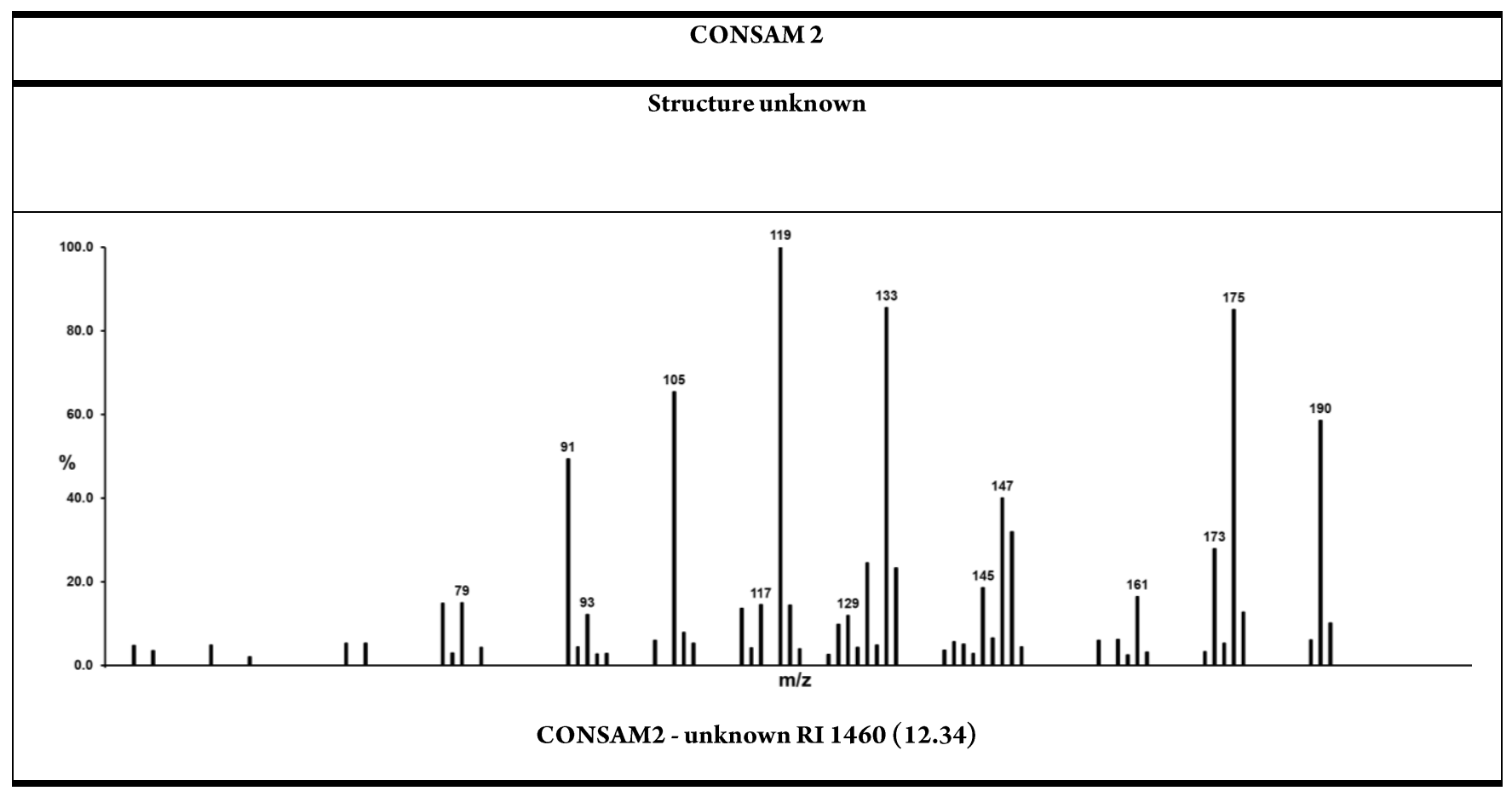




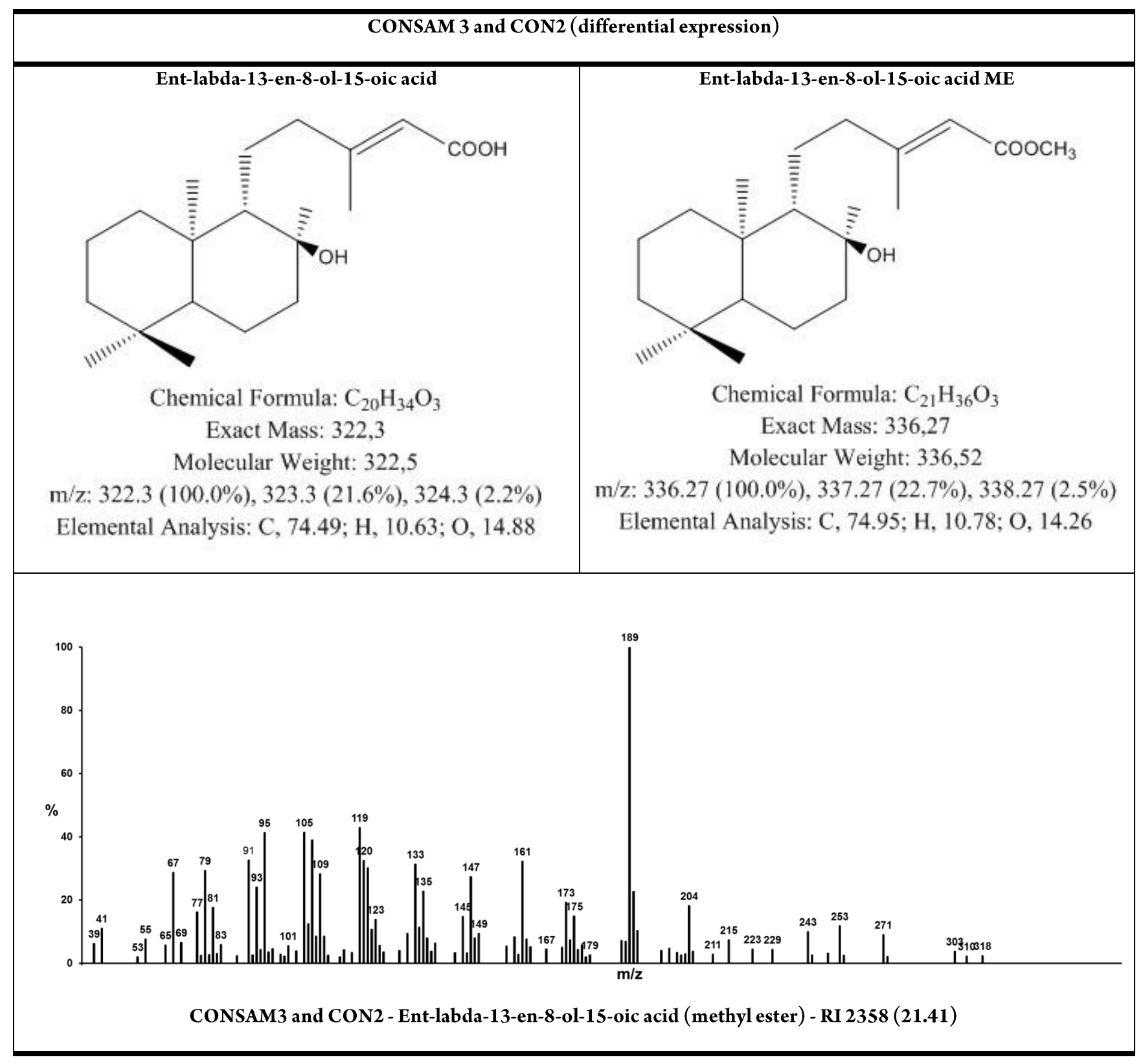




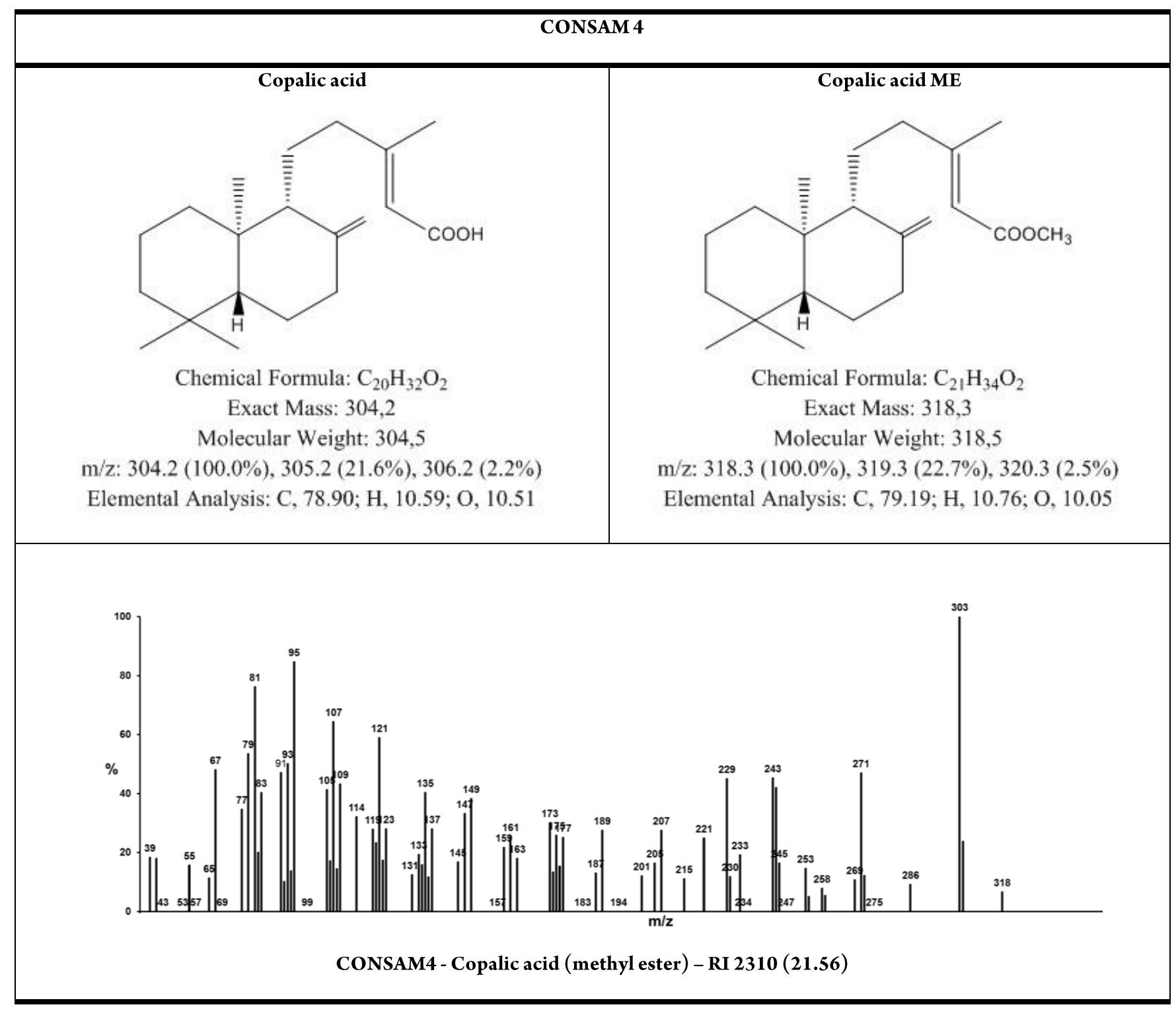




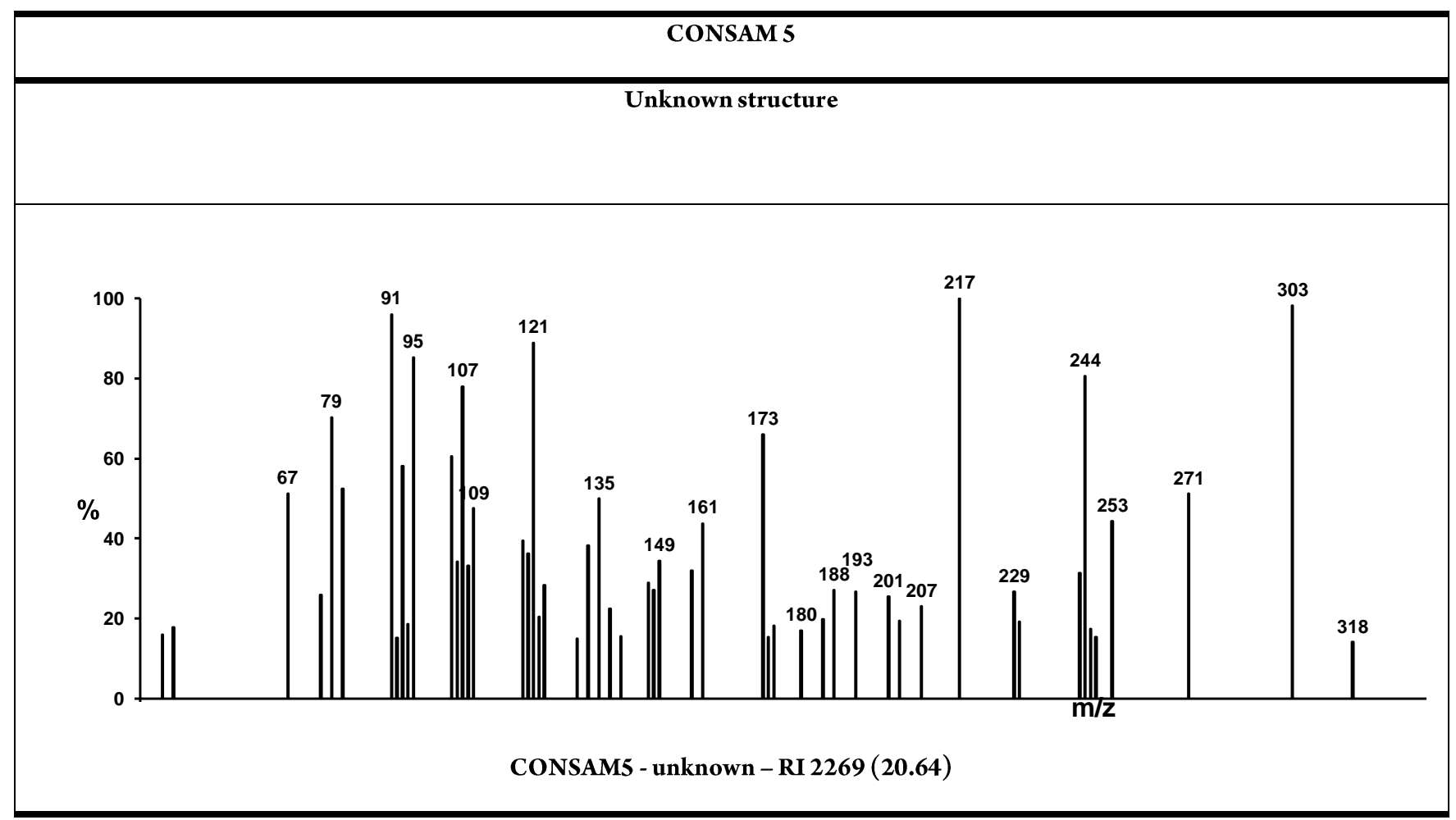




\section{SANMAN1}

coelution of SAN2 and MAN5

\section{RI 2500 (22.61)}

\section{SANMAN2}

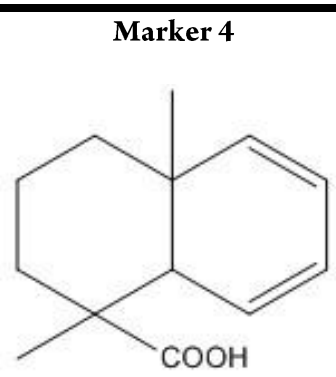

Chemical Formula: $\mathrm{C}_{13} \mathrm{H}_{18} \mathrm{O}_{2}$

Exact Mass: 206,13

Molecular Weight: 206,29

$\mathrm{m} / \mathrm{z}: 206.13(100.0 \%), 207.13(14.1 \%)$

Elemental Analysis: C, 75.69; H, 8.80; O, 15.51
Marker 4 ME

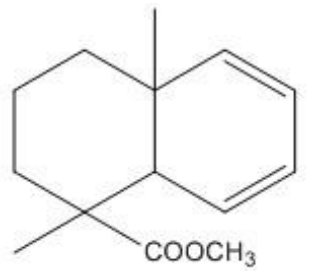

Chemical Formula: $\mathrm{C}_{14} \mathrm{H}_{20} \mathrm{O}_{2}$

Exact Mass: 220,15

Molecular Weight: 220,31

m/z: $220.15(100.0 \%), 221.15(15.1 \%), 222.15$

$(1.1 \%)$

Elemental Analysis: C, 76.33; H, 9.15; O, 14.52

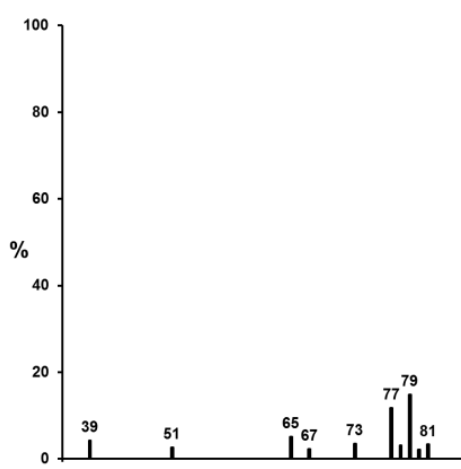

SANMAN2 - Marker 4 (generated by pyrolytic degradation of sandarac and Manila copal) - RI 1593 (13.95) 


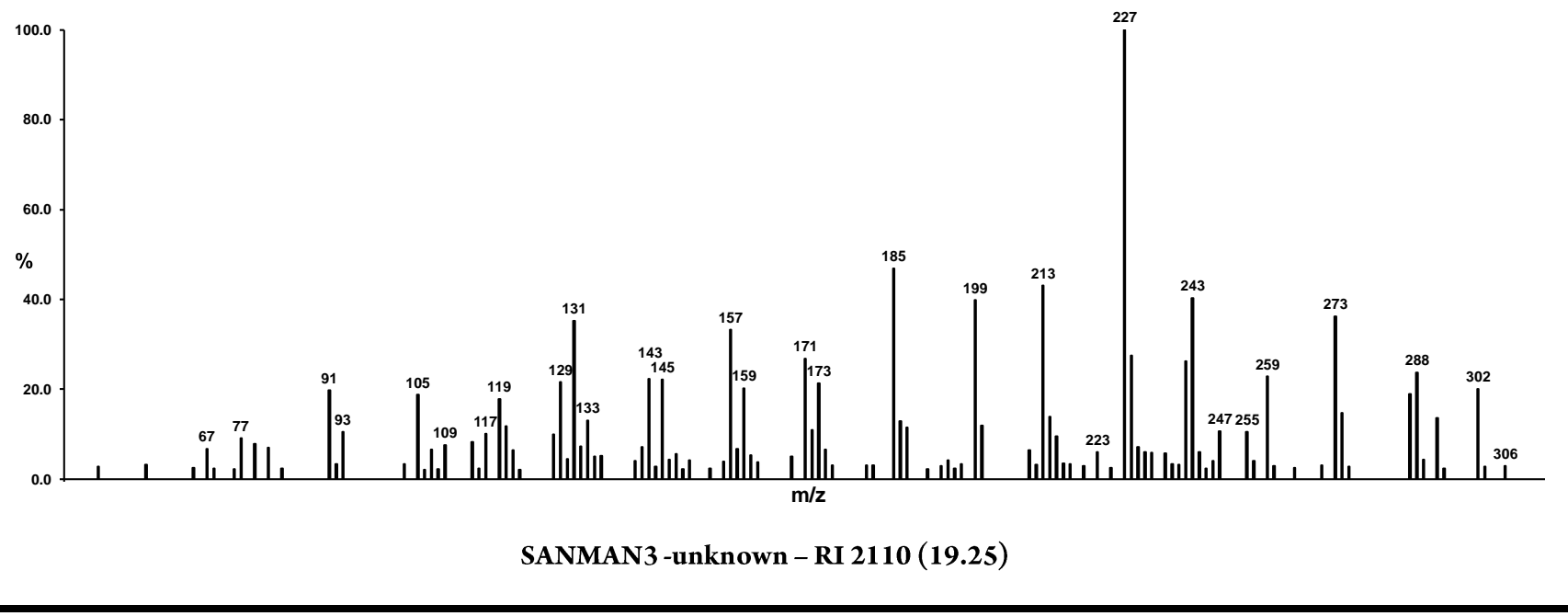




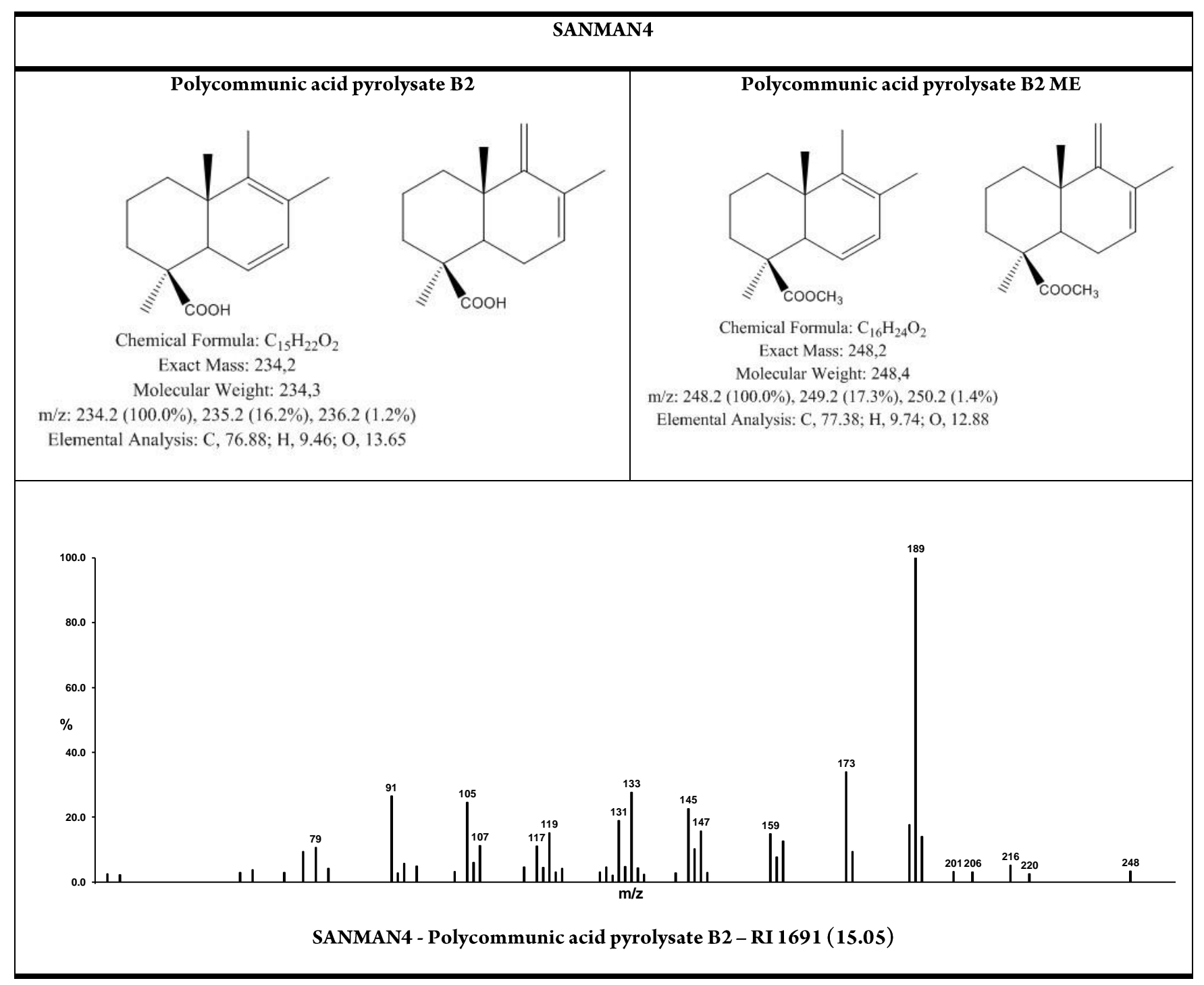




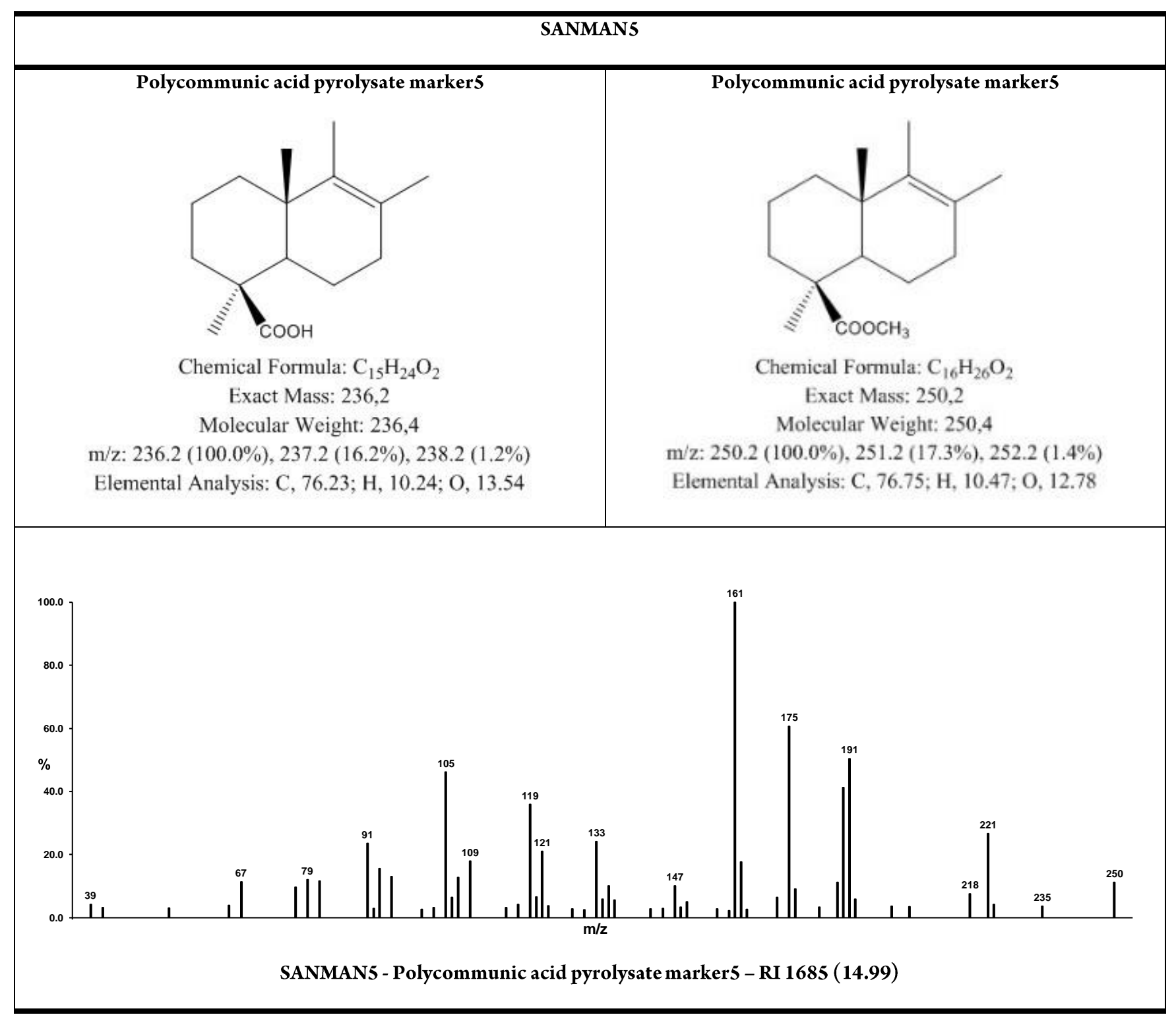




\section{SAN1}

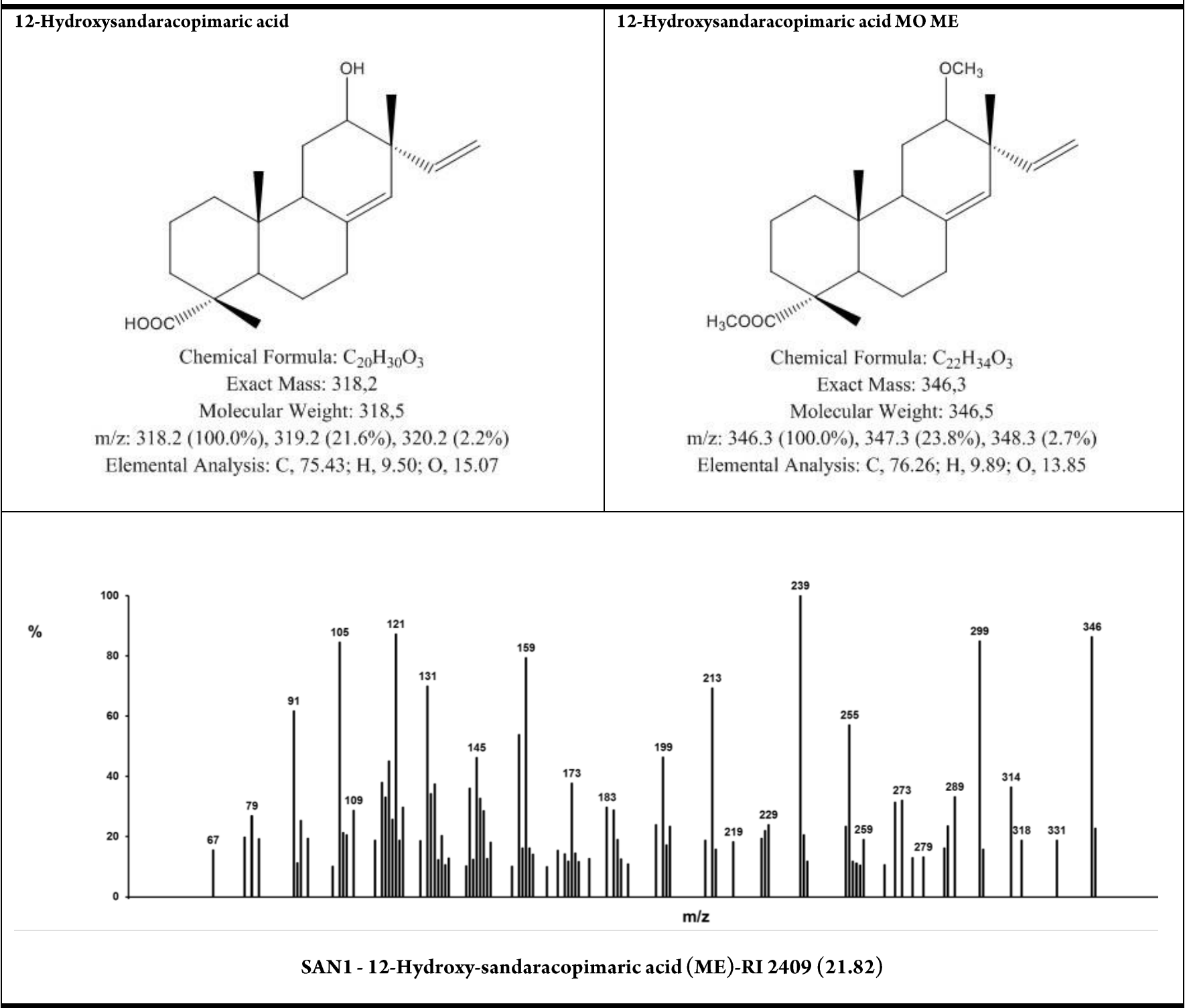




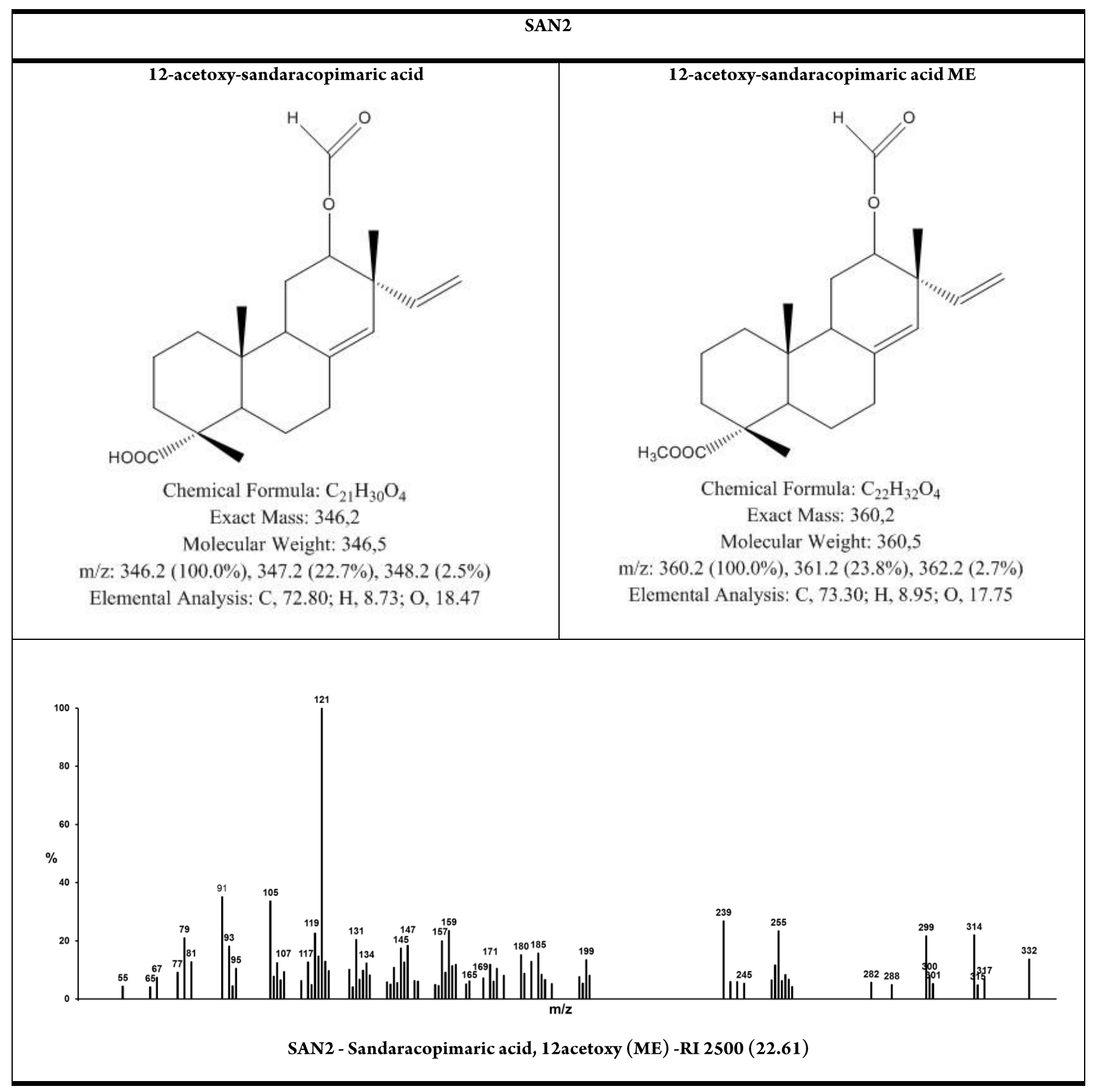




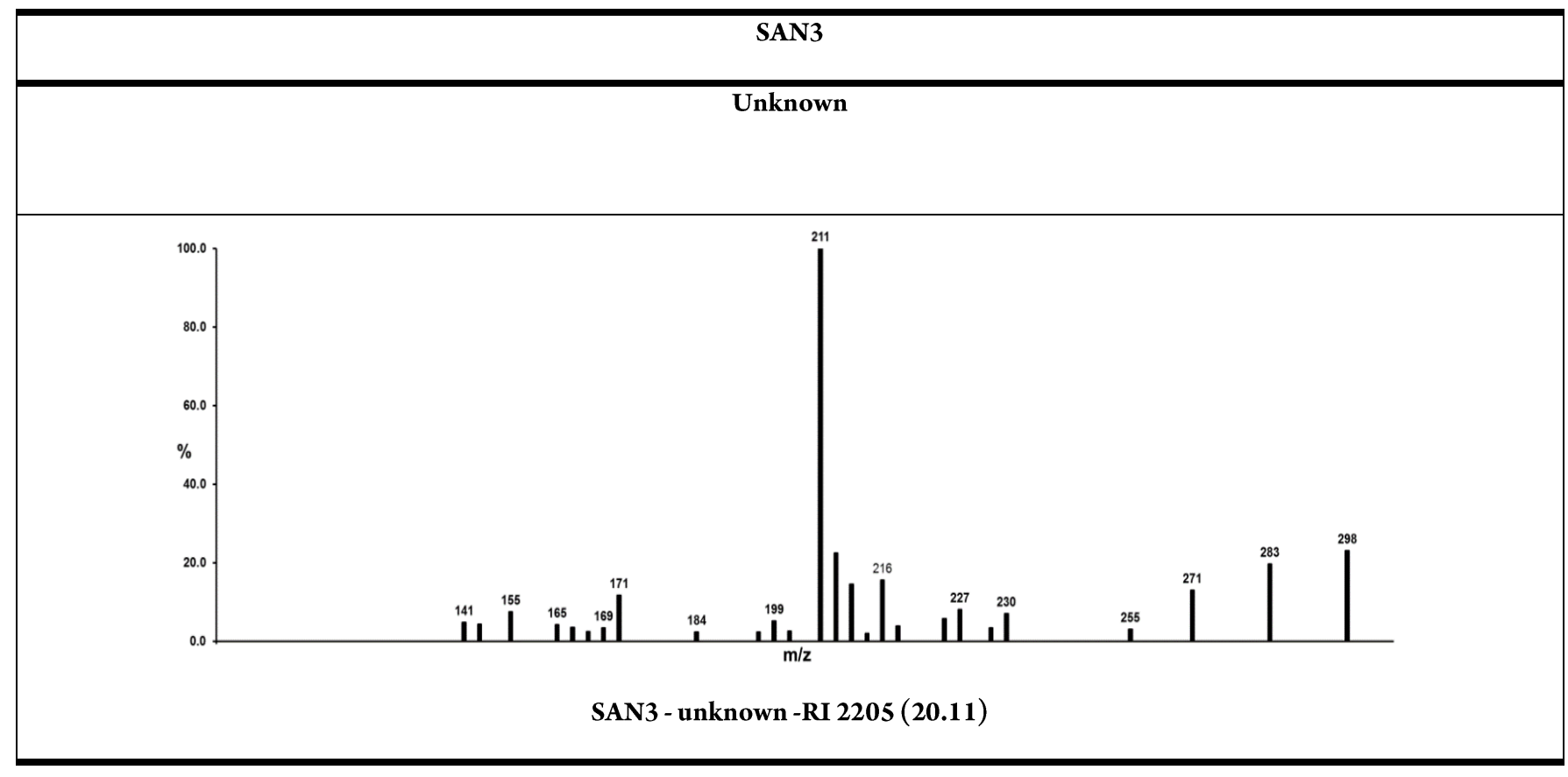




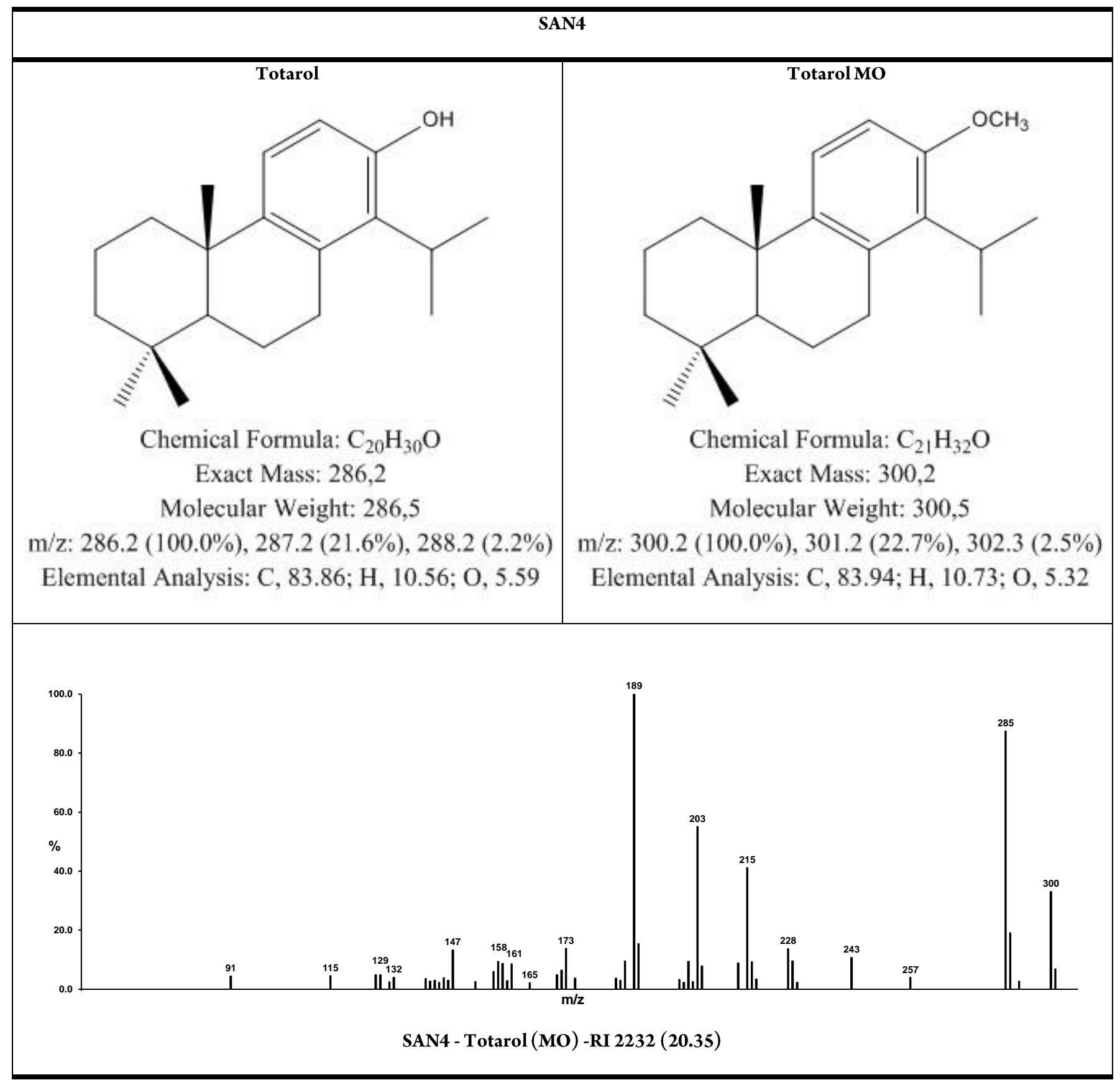




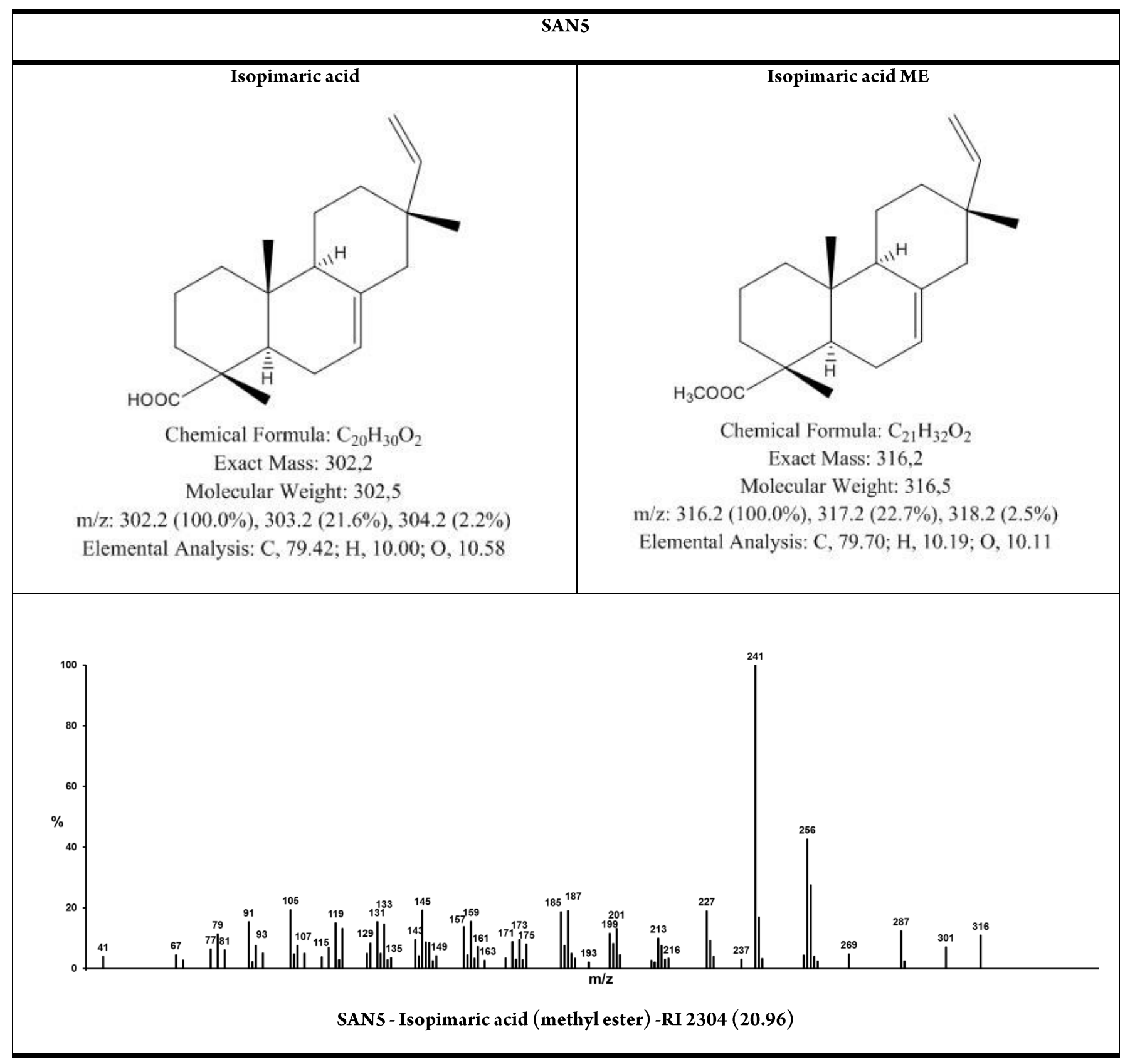




(two isomers)




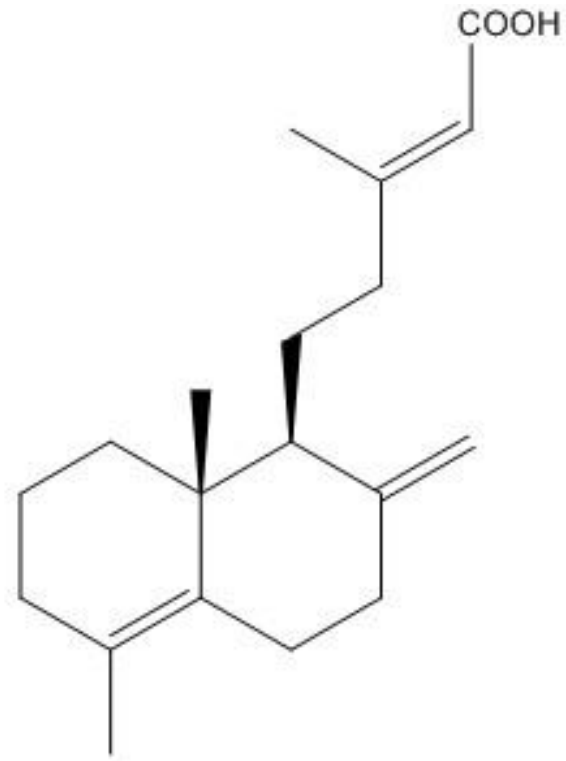

Chemical Formula: $\mathrm{C}_{19} \mathrm{H}_{28} \mathrm{O}_{2}$

Exact Mass: 288,2

Molecular Weight: 288,4

$\mathrm{m} / \mathrm{z}: 288.2(100.0 \%), 289.2(20.5 \%), 290.2(2.0 \%)$

Elemental Analysis: C, 79.12; H, 9.79; O, 11.09

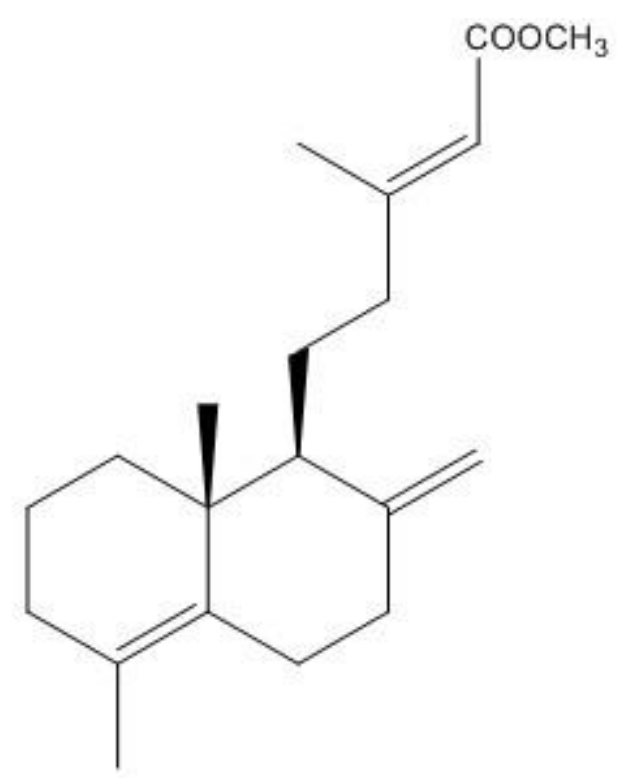

Chemical Formula: $\mathrm{C}_{20} \mathrm{H}_{30} \mathrm{O}_{2}$

Exact Mass: 302,2

Molecular Weight: 302,5

$\mathrm{m} / \mathrm{z}: 302.2$ (100.0\%), $303.2(21.6 \%), 304.2(2.2 \%)$

Elemental Analysis: C, $79.42 ; \mathrm{H}, 10.00 ; \mathrm{O}, 10.58$

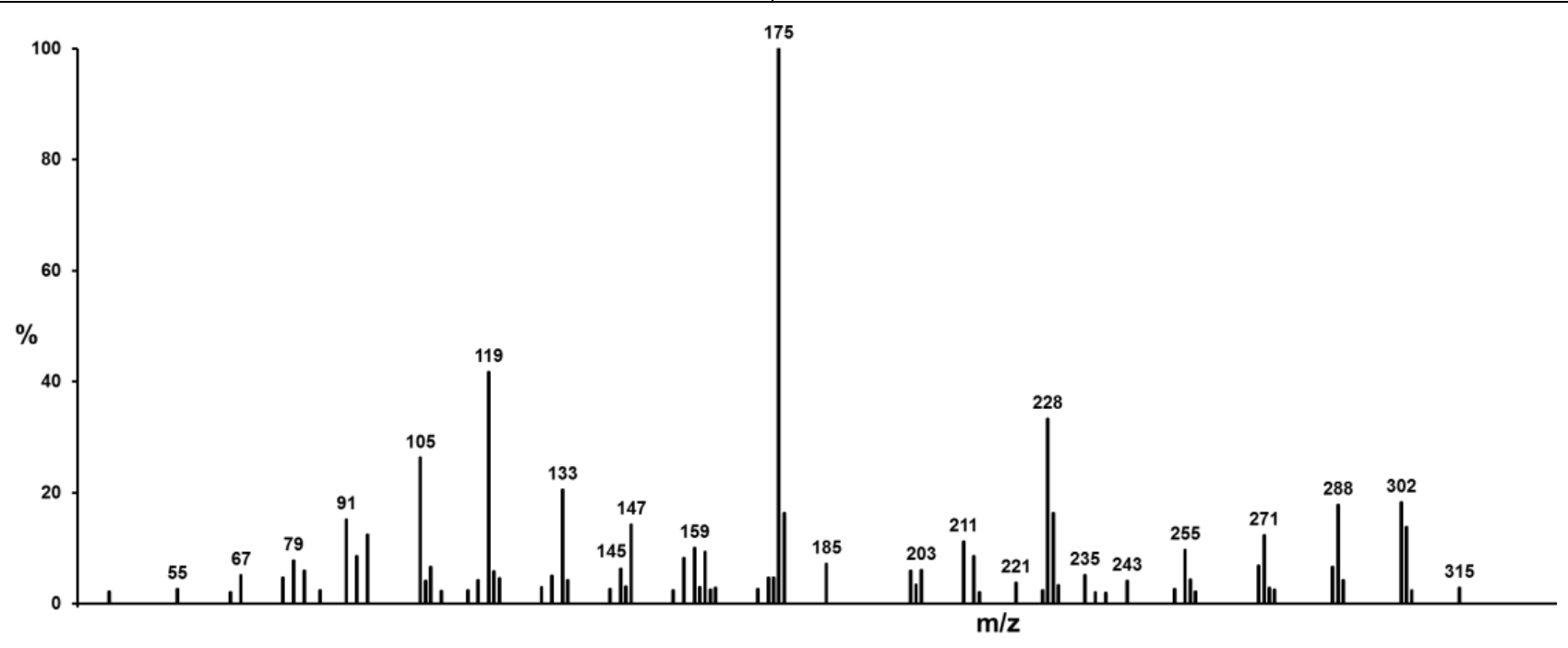

MAN2 - Methyl 19-norlabda-4.8(20),13-trien-15-oate -RI 2445 (21.53) 


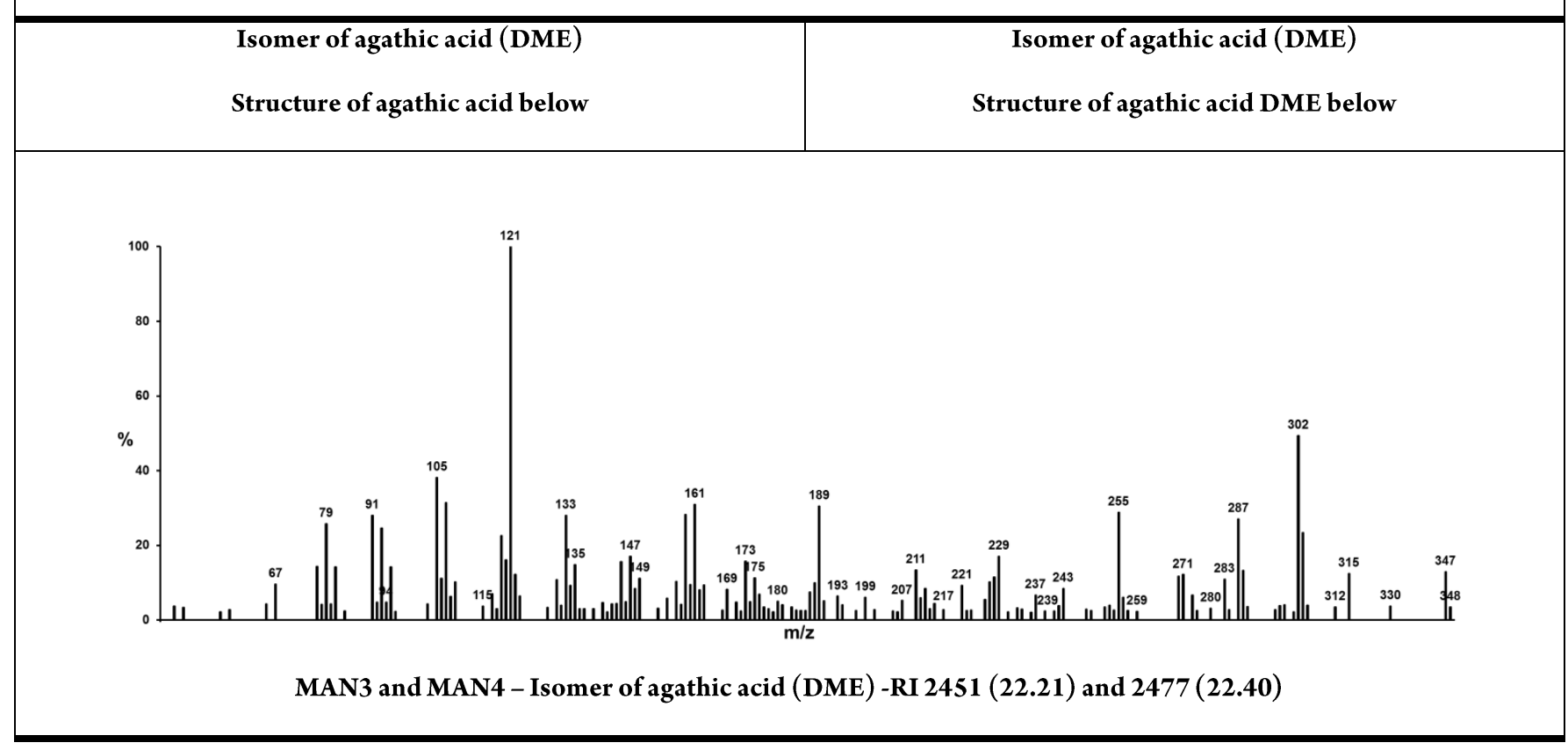

Molecular Weight: 334,46
Exact Mass: 334,21
m/z: 334.21 (100.0\%), $335.22(21.6 \%), 336.22(2.2 \%)$
Elemental Analysis: $\mathrm{C}, 71.82 ; \mathrm{H}, 9.04 ; \mathrm{O}, 19.13$



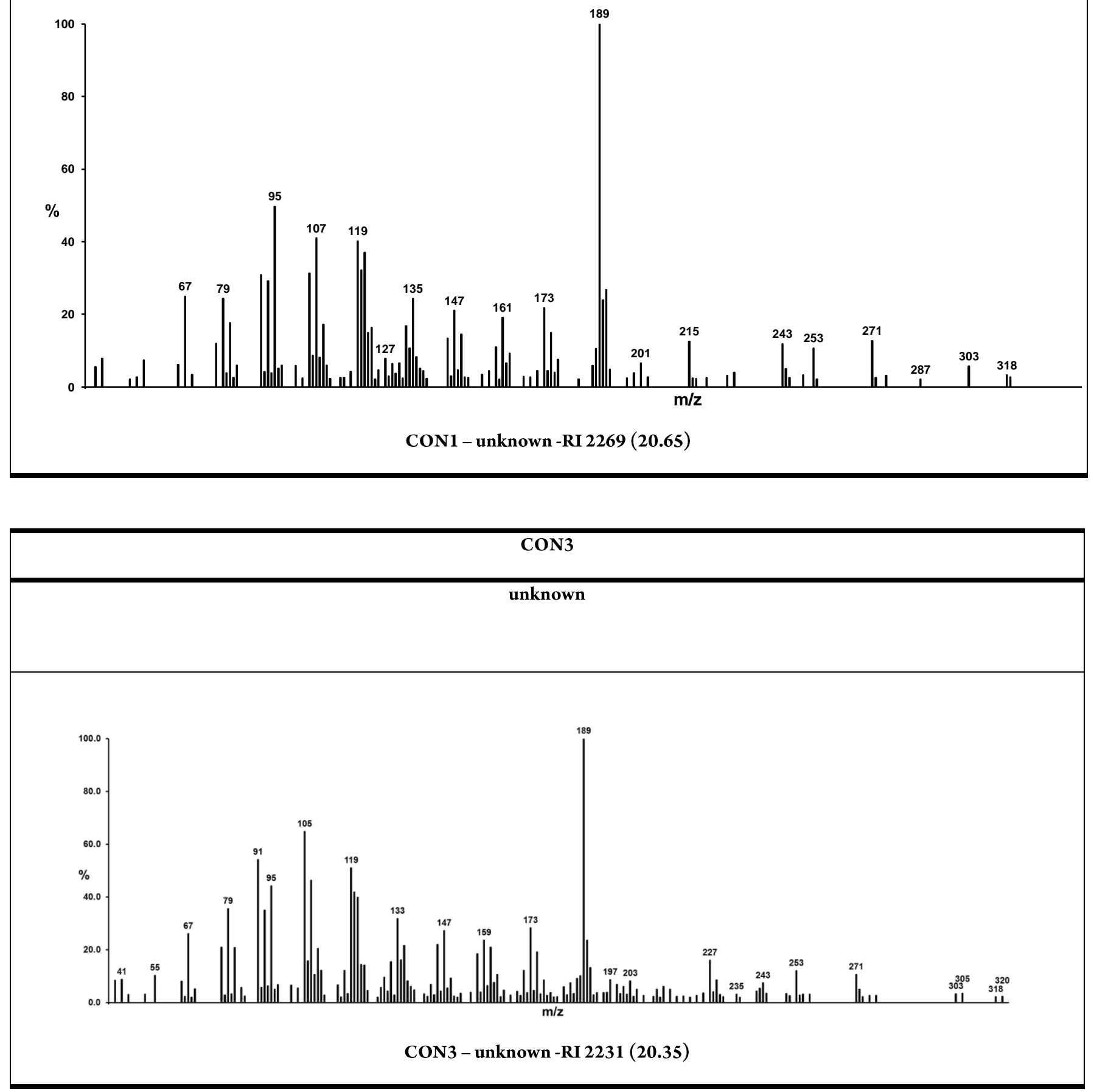


\section{SAM1}

unknown

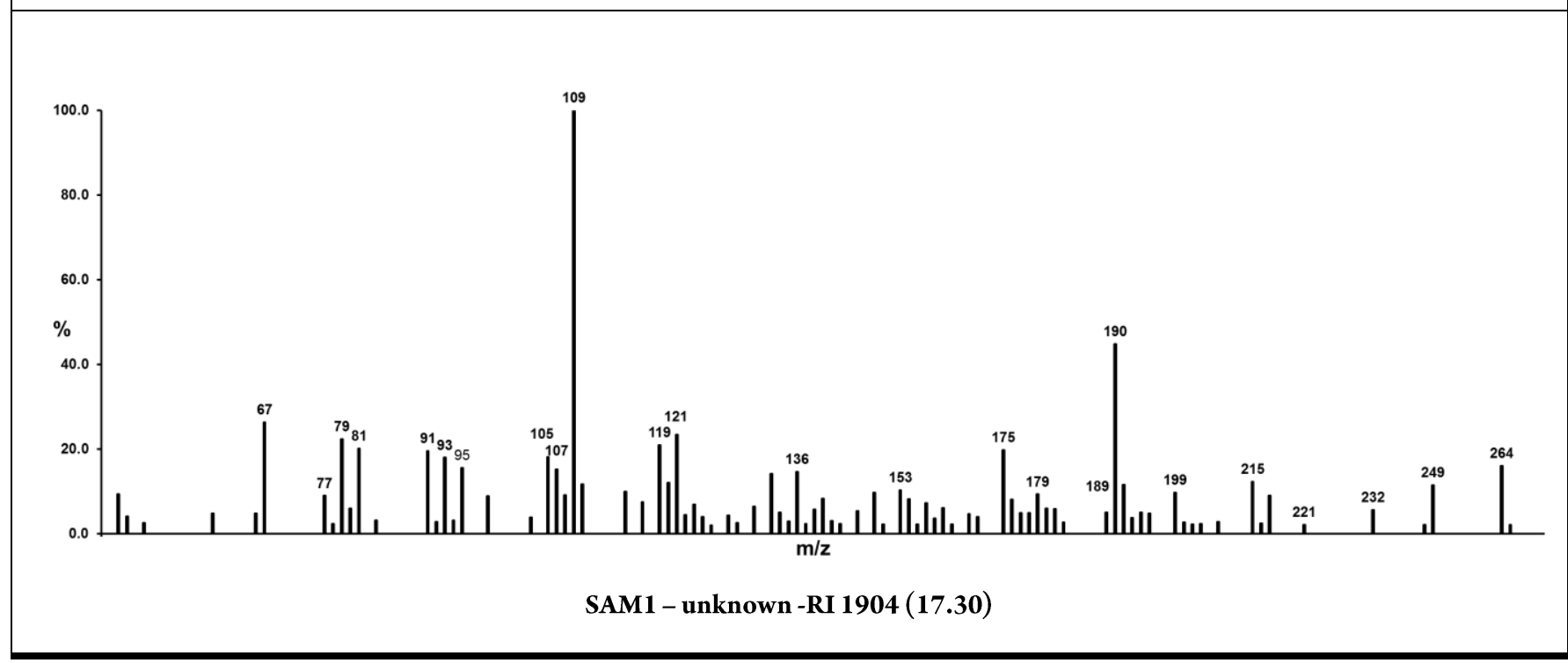

SAM2

unknown

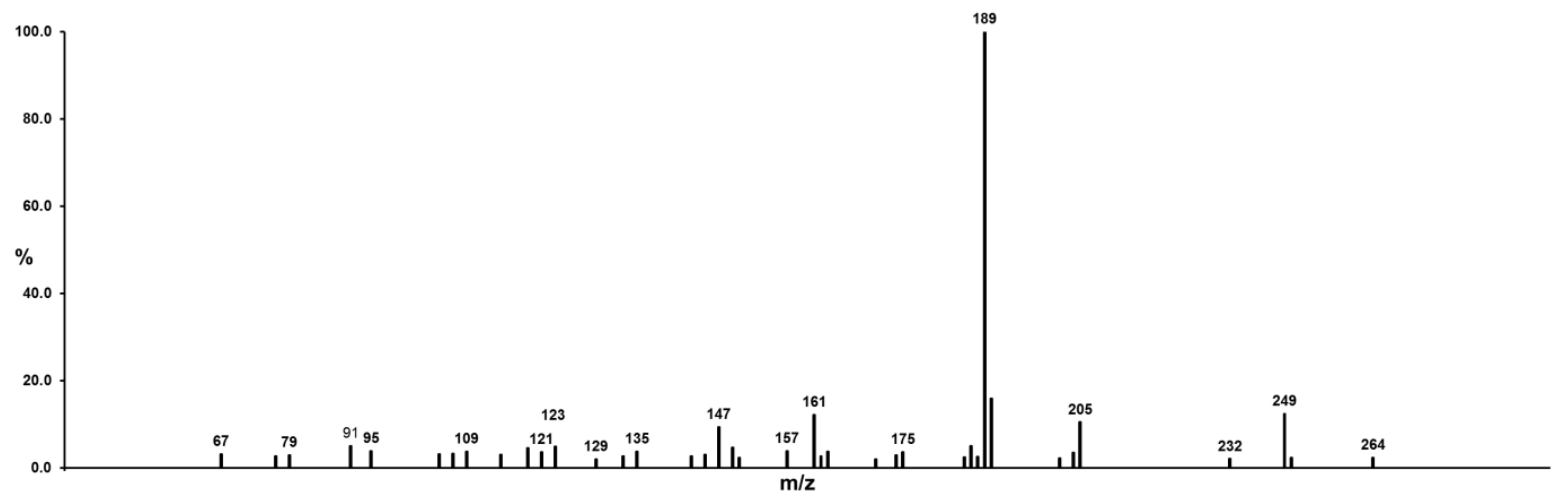

SAM2 - unknown -RI 2074 (18.93) 


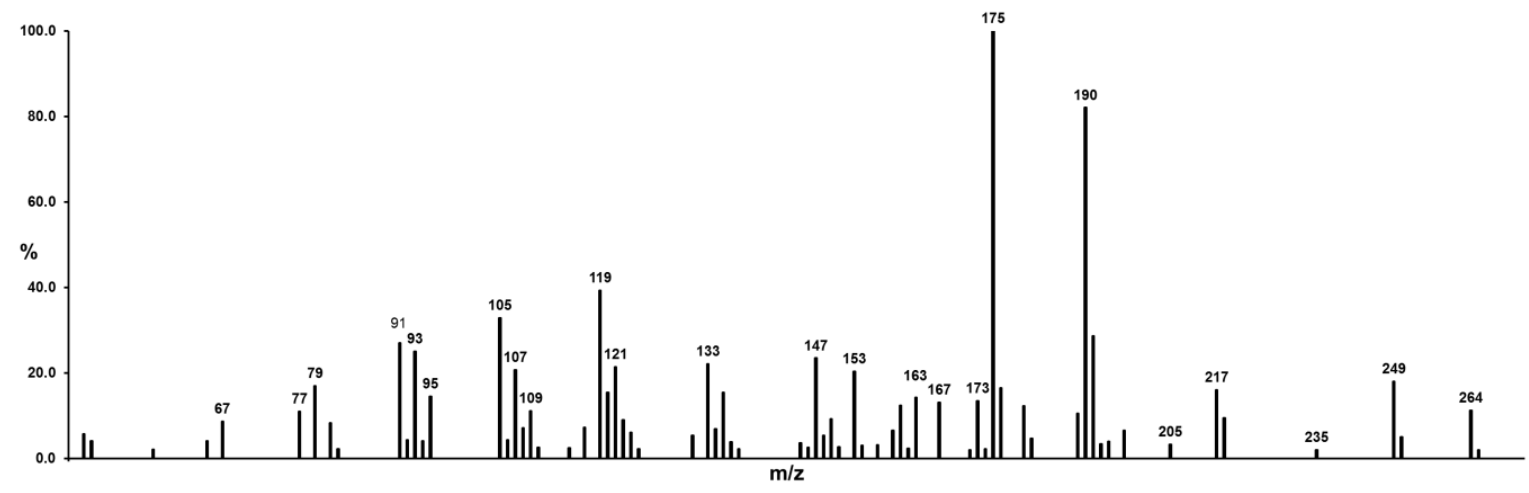

SAM3 - unknown -RI 1852 (16.76)

SAM4

unknown

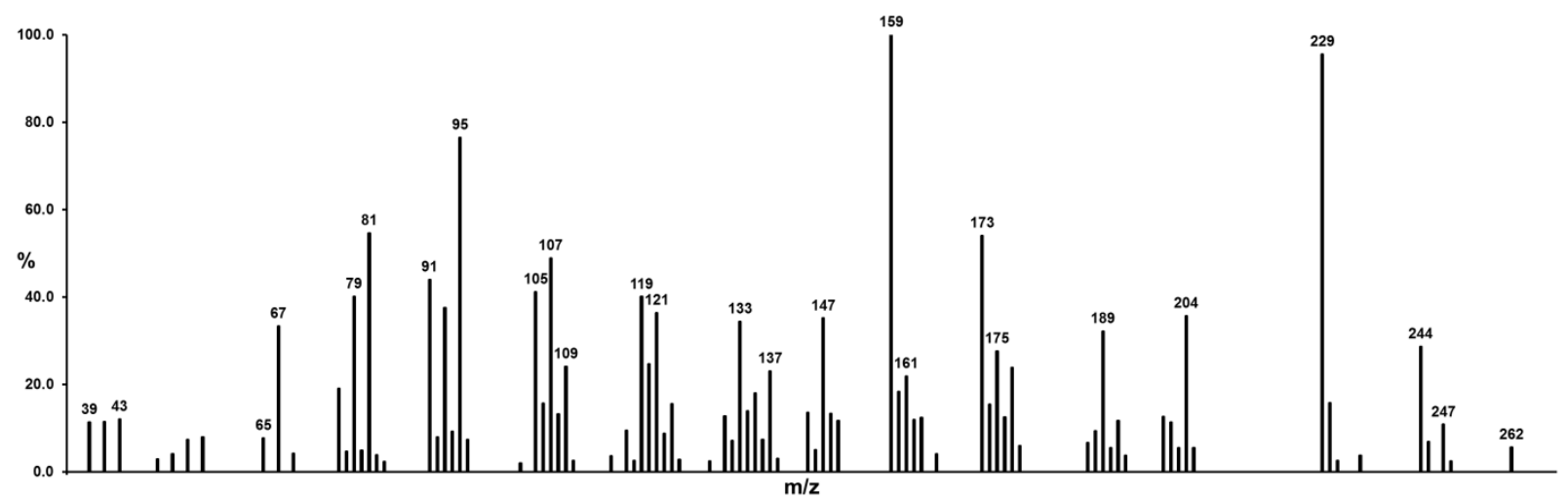

SAM4 - unknown -RI 1956 (17.81) 


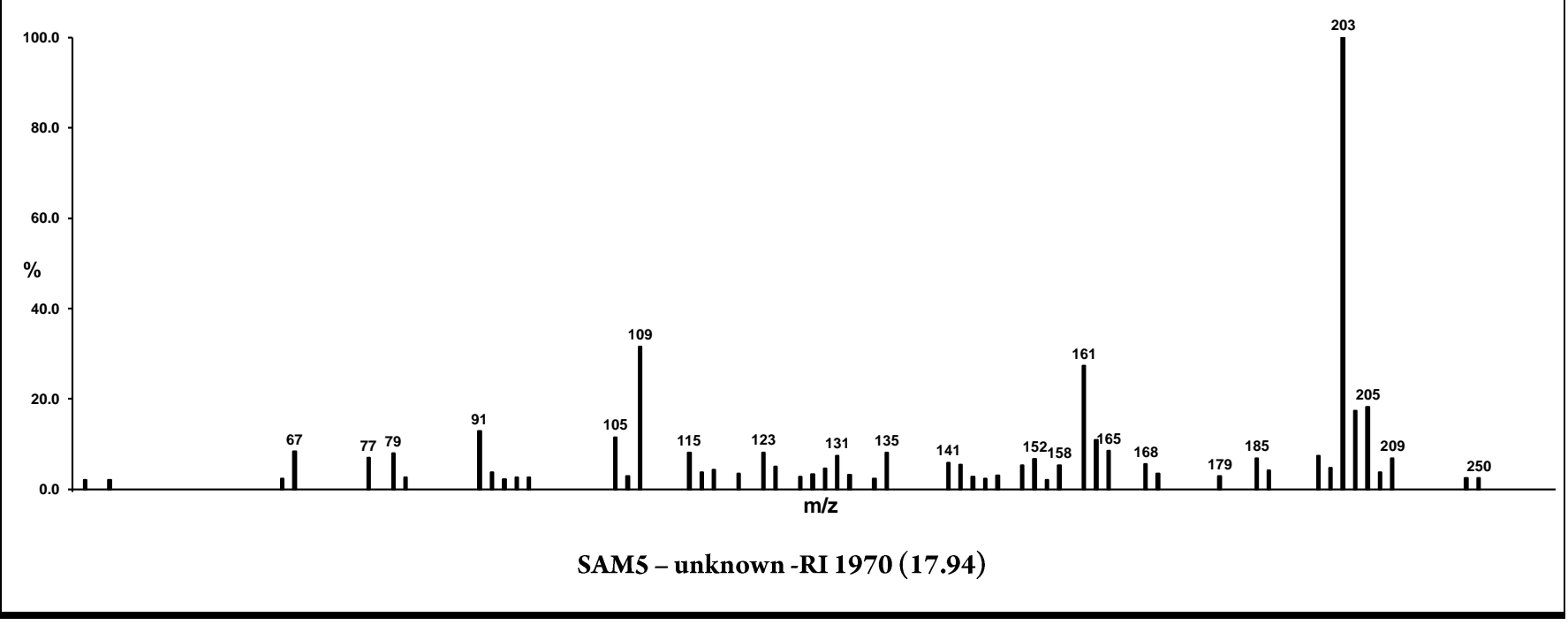




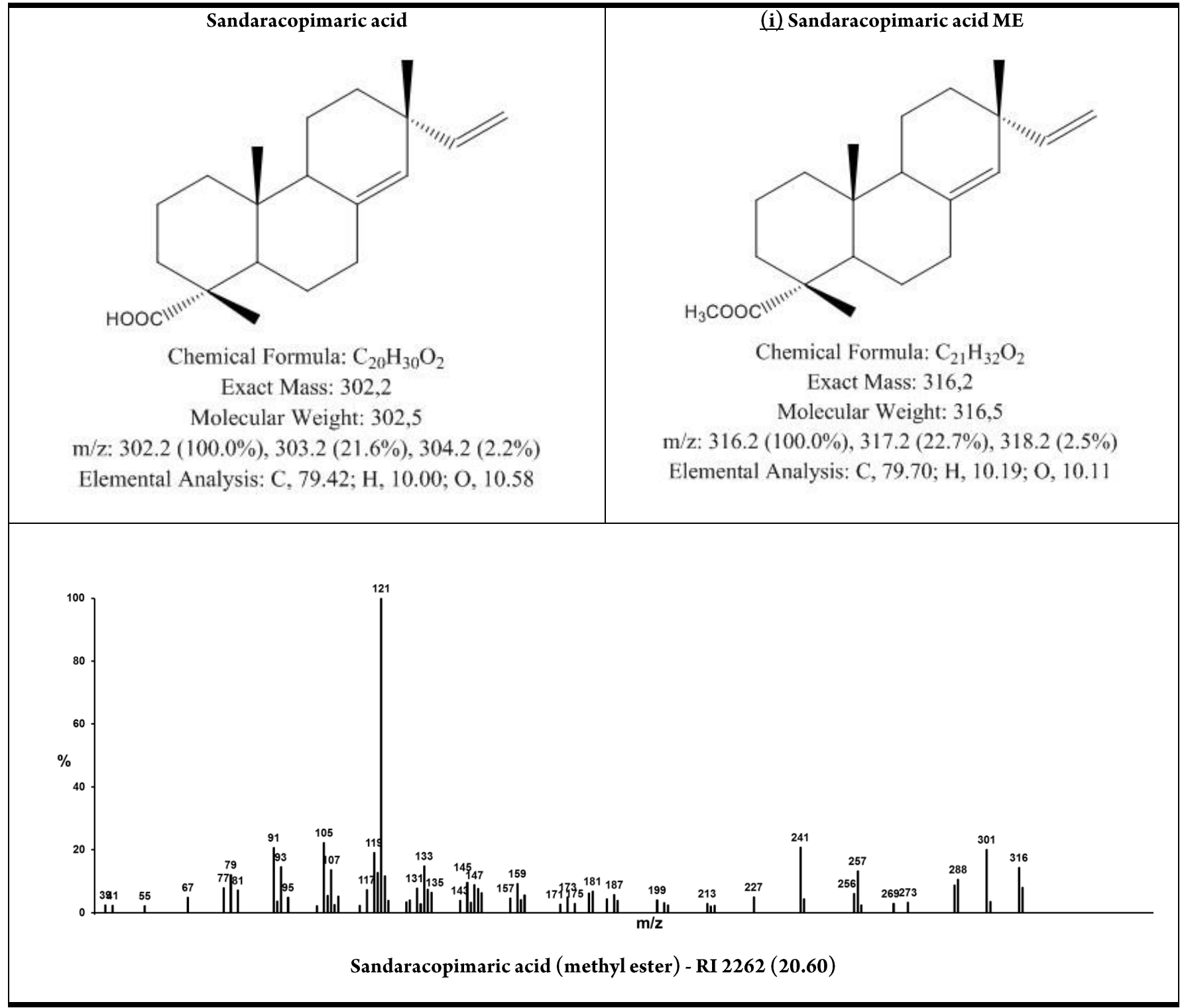




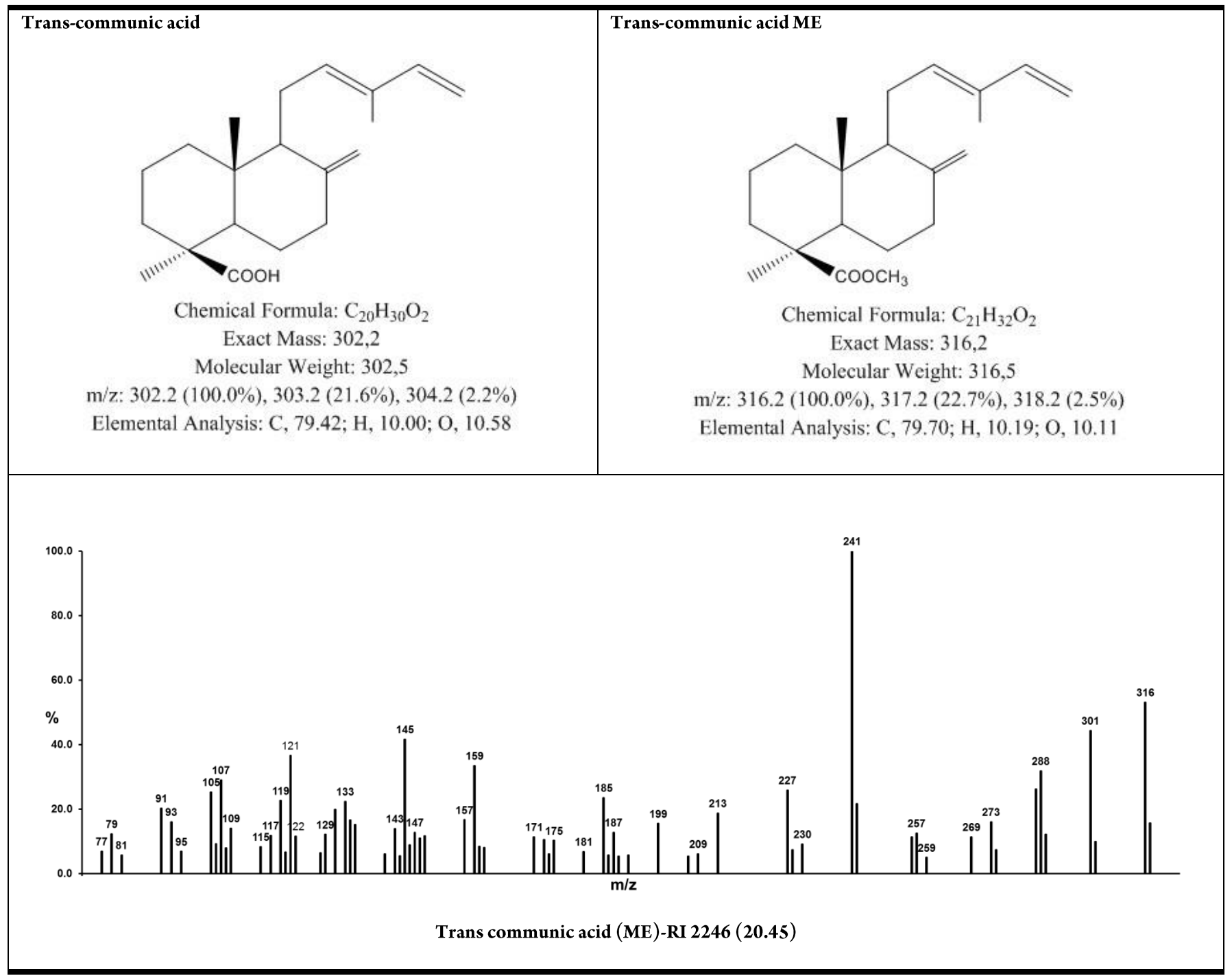

